\title{
O DIREITO À EDUCAÇÃO INCLUSIVA E SUA RELAÇÃO COM O ESTADO, $O$ \\ CAPITAL E A SOCIEDADE \\ (Entraves à efetivação da inclusão escolar)
}

\author{
Graziella Montes Valverde ${ }^{1}$
}

\section{RESUMO}

O Estado, muitas vezes, legisla sobre temas carentes de regulação, alcançando alguns grupos excluídos, especialmente no que se refere aos direitos sociais. Contudo, nem sempre estas leis melhoram, garantem e legitimam um direito. Toda norma jurídica elaborada pelo Estado deve produzir, principalmente, efeito social, não apenas jurídico. O objetivo deste artigo é analisar a necessidade de as pessoas com deficiência terem acesso à educação inclusiva para sua emancipação social e para seu desenvolvimento enquanto cidadãs. Para a elaboração deste artigo utilizou-se a revisão bibliográfica, essencialmente 'Poderá o Direito ser Emancipatório' de Boaventura de Sousa Santos.

Palavras-chave: Direitos à Educação Inclusiva; Emancipação Social; Estado; Políticas Públicas; Sociedade.

\section{THE RIGHT TO INCLUSIVE EDUCATION AND ITS RELATIONSHIP WITH STATE, CAPITAL AND SOCIETY \\ (Obstacles to the effectiveness of school inclusion)}

\begin{abstract}
The state often legislates on subjects lacking regulation, reaching some excluded groups, especially with regard to social rights. However, these laws do not always improve, guarantee and legitimize a right. Any legal norm elaborated by the State must produce, mainly, social effect, not only legal. The purpose of this article is to analyze the need for people with disabilities to have access to inclusive education for their social emancipation and for their development as citizens. For the elaboration of this article we used the bibliographical revision, essentially 'It will be the Right to be Emancipatory' of Boaventura de Sousa Santos.
\end{abstract}

Keywords: Rights to Inclusive Education; Social Emancipation; State; Public Policy; Society.

\section{INTRODUÇÃO}

\footnotetext{
${ }^{1}$ Mestranda em Direito e Inovação pela Universidade Federal de Juiz de Fora (UFJF). Possui graduação em Direito pelo Instituto Ensinar Brasil (2014) e graduação em Administração pela Faculdade Metodista Granbery (2006). Tem experiência na área de Direito, com ênfase em Direito. Atua como advogada nas áreas: cível, trabalhista e previdenciária.
} 
Ao se falar em educação em um país em desenvolvimento e com crises de ordem econômica, política e social, a tarefa de se tentar igualar o acesso à educação se torna complicada, já que dependerá de muito investimento e de políticas públicas, para a implantação de processos especiais para a efetivação da educação inclusiva. A exclusão das pessoas com deficiência foi um processo construído histórica e culturalmente.

A Constituição Brasileira de 1988, em seu artigo 208, bem como os artigos 58, 59 e 60 da Lei de Diretrizes e Bases da Educação Nacional asseguram direitos educacionais inclusivos. Diversas são as leis que definem parâmetros para a inclusão de alunos com deficiência em classe comum da rede regular de ensino. Porém, frequentemente, o educando com deficiência se vê apenas integrado ao meio educacional, sem qualquer suporte à efetivação de seu desenvolvimento. O direito à educação inclusiva é elemento necessário à formação da cidadania e à emancipação social das pessoas com deficiência.

Além das normatizações, há muito já existentes, para a adequação e concretização da inclusão escolar brasileira, em 2015 foi promulgada a nova Lei de Inclusão Brasileira (Lei no 13.146/15 - Estatuto da Pessoa com Deficiência), impondo novas regras para assegurar e promover, em condições de igualdade, o exercício dos direitos e das liberdades fundamentais para a emancipação, inclusão social e cidadania de tais pessoas.

A Declaração Universal dos Direitos Humanos de 1948 (DUDH) contribuiu para o avanço ao respeito dos direitos humanos em ordem internacional. No Brasil, nos últimos 30 anos, desde a promulgação da $\mathrm{CF} / 88$, houve um avanço na garantia e efetivação dos direitos sociais no âmbito do Poder Judiciário. Entretanto, o Poder Legislativo, ao mesmo passo que elabora leis e tenta cobrir as lacunas existentes, também se vê engajado nas limitações e na elaboração de outras leis que retiram direitos ou possibilidades de se efetivar progresso nas conquistas sociais.

Por isso, deve haver um grande envolvimento do Poder Público a fim de proporcionar meios exequíveis para a efetivação plena das normatizações trazidas pela lei de inclusão. A elaboração de muitas leis é suficiente para a efetivação plena de um direito, ou quando se fala em investimentos em direitos sociais e políticas públicas ficamos apenas no plano da normatividade e não da práxis?

Logo, identifica-se a seguinte problemática a ser analisada neste trabalho: mesmo diante da vasta legislação que protege os direitos das pessoas com deficiência, ainda há obstáculos a serem enfrentados para a efetiva inclusão dessas pessoas? 
Há que se distinguir, portanto, os contrastes e a distância entre a normatividade e sua aplicação no caso concreto, e, ainda, as implicações desta prática pelo Estado. Mesmo com tantas legislações que circundam as questões inerentes aos direitos das pessoas com deficiência, não significa que os problemas que as envolvam foram sanados ou minimizados. Não se pode pensar que apenas pela existência das leis e orientações escritas, o contexto social tenha mudado para melhor. Ao contrário, corre-se o risco de que, até por esse motivo, ocultem-se problemas sociais e suas soluções.

A emancipação social pode ser facilitada pelo Direito, como por vezes, o Direito (no caso, as leis) pode até mesmo encobrir ou ocultar um problema social. Muitas vezes, a existência de variadas normatizações pode mascarar a resolução dos problemas. Pela simples elaboração das leis, a questão por ela tratada parece estar resolvida, pois já existe determinada norma que assegura tal direito. Com isso, outro problema poderá ser criado: a lei para sanar aquela situação até então não solucionada não é aplicada, apenas existe.

Em perspectivas que pugnam por uma emancipação desses indivíduos para sua inserção plena na sociedade e a efetivação de sua cidadania, é necessária uma análise cuidadosa das causas que impedem e limitam a inclusão escolar: (1) o Estado legisla de forma eficaz, mas e a execução?; (2) os recursos públicos são suficientes à efetivação do direito social à educação inclusiva? E, por último: (3) a sociedade, a família e o Estado estão envolvidos para promover a verdadeira inclusão escolar das pessoas que necessitam de cuidados especiais?

São muitos os entraves à efetivação do direito à educação inclusiva. Ações e estratégias deverão ser traçadas para que não se concretize maior exclusão e mais invisibilidade às classes preteridas. As leis que abarcam os direitos de inclusão das pessoas com deficiência devem proporcionar meios capazes de contribuir com seu desenvolvimento enquanto cidadãs e com sua emancipação social.

A modernidade trouxe a tensão entre a regulação do Estado e a emancipação social. Dessa forma, este artigo se justifica pela necessidade de as pessoas com deficiência serem realmente incluídas no ambiente escolar e na sociedade como um todo, tendo em vista sua segregação ao longo da história.

Tal análise será apresentada com base em estudiosos da educação e especialmente a teoria da emancipação social de Boaventura de Sousa Santos. A igualdade e a liberdade, dois princípios democráticos relevantes na perspectiva da emancipação social, deverão ser 
aplicados através da efetividade do direito à educação, especialmente à educação inclusiva. Poderá o Direito ser realmente emancipatório diante de tantas leis ineficazes?

Para atingir os objetivos acima elencados, utilizou-se o levantamento bibliográfico, a fim de delinear o referencial teórico e analisar as diversas previsões legais sobre o direito à educação inclusiva. De acordo com Lee Epstein e Gary King (2013, p. 47, 57 e 72), este trabalho deverá ser replicável e contribuirá para literatura acadêmica, dada sua efetivação como um empreendimento social.

Este artigo se divide em três eixos, sendo o primeiro uma reflexão sobre o valor oculto das leis inclusivas e as consequências de sua inefetividade em um Estado Democrático, o segundo aponta os entraves às políticas de educação inclusiva e o terceiro demonstra a ineficiência das legislações educacionais inclusivas e os obstáculos à efetivação dos Direitos Humanos às pessoas com deficiência.

\section{O valor oculto das leis inclusivas e as consequências da sua inaplicabilidade em um}

\section{Estado Democrático}

As leis da Antiguidade não se mostraram favoráveis às pessoas com deficiência. $\mathrm{Na}$ Roma antiga era permitido, por lei, que os pais matassem, pela prática do afogamento, os filhos que nascessem com alguma deformidade física (GUGEL, 2007). Segundo a autora, o século XX trouxe avanços importantes para as pessoas com deficiência, sobretudo em relação às ajudas técnicas ou elementos tecnológicos assistivos. A sociedade se organizou para enfrentar os problemas e para melhor atender essa classe (GUGEL, 2007).

A Declaração Universal dos Direitos Humanos de 1948 (DUDH), reconhece no artigo 26 que "toda pessoa possui direito à educação". Todavia, há um distanciamento entre as previsões normativas e a realidade no Brasil, visto que o precário ensino público e a exclusão social vivenciada pelas pessoas com deficiência, impedem que essa minoria usufrua desse direito de forma adequada. O descaso com os deficientes é o modelo institucionalizado da invisibilidade.

A DUDH orientou para o acesso universal e igualitário à educação em todo o mundo. Contudo, o direcionamento que foi dado ao ensino e a esse direito que se fez concretizar para todos não tem se mostrado a melhor forma de se percorrer um caminho rumo ao desenvolvimento humano e social (IBGE, 2018). 
Desde 1961, bem antes da atual Constituição Brasileira, o artigo 88 da Lei n ${ }^{\circ}$ 4.024, Lei de Diretrizes e Bases da Educação Nacional (LDBEN), revogada quase em sua totalidade pela Lei 9.394/96, já tratava da educação dos excepcionais, nomenclatura utilizada à época. Ela previa a integração dos alunos com algum tipo de deficiência no sistema geral de educação com toda comunidade.

A visão e as discussões sobre as pessoas com deficiência foram se alterando conforme a época e por isso a deficiência é um conceito cultural e historicamente construído. Pelas nomenclaturas utilizadas no passado, verifica-se a discriminação e o preconceito cultuado ao longo do tempo. As pessoas com deficiência eram chamadas de retardadas mentais, anormais, mongoloides, diferentes, dentre outros.

Deste modo, faz-se necessária a quebra do paradigma da anormalidade cultivado pela sociedade. Tanto tratamento desumano e desigual despendido a essa camada só fez por excluir ainda mais essas pessoas tidas como diferentes. Neste sentido, Santos (1999a, p. 2) identifica a desigualdade como um fenômeno sócio-econômico e a exclusão como um fenômeno cultural, social e de civilização.

Diante disso, há que se falar em intervenção estatal, para tentar corrigir ou pelo menos amenizar as falhas, exclusões e desigualdades que se construíram ao longo do tempo. A atividade legislativa, regularmente, vem desempenhando esta função através de normas, regulamentos e leis. É preciso verificar se os ordenamentos abstratos em relação à educação inclusiva estão produzindo os efeitos sociais e averiguar se as pessoas com deficiência são realmente incluídas. Qual o teor valorativo das leis? As leis existem apenas para suprir lacunas no sistema normativo e corrigir erros históricos?

O universo das normas inclusivas das pessoas com deficiência é amplo. São leis, decretos, portarias, resoluções, aviso e documentos internacionais (convenções, carta, declarações e conferência). Contudo, de que adiantam tantas normas, se estas, muitas vezes, são elaboradas pelo legislativo para cumprir sua função, mas o Poder Público nada mais faz a não ser deixá-las no papel como letras mortas?

A Constituição Federal de 1988 determinou a inclusão do aluno deficiente na rede regular de ensino. Com toda essa inserção legislativa, acredita-se que o problema foi resolvido. Porém, o que ocorre é maior dificuldade no processo emancipatório das pessoas com deficiência, as quais sofrem, até hoje, grande discriminação social por toda sociedade e até mesmo pelo Poder Público. 
De acordo com Santos (2003, p. 7) os Estados liberais projetaram uma tensão entre a regulação e a emancipação social que acabou por cristalizar exclusões estruturais (de tipo política, econômica ou social). O autor afirma que "não há memória coletiva de luta ou movimentos empreendidos em nome da 'emancipação social' (2003, p. 9).

Ao se tentar incluir um aluno que necessita de cuidados especiais no ensino regular, de acordo com as legislações vigentes sobre educação especial inclusiva, corre-se o risco de se promover mais exclusão. Se não forem observados detalhes para a promoção da plena inclusão, que esse público demanda para ser, de fato, inserido no quadro social educacional, as pessoas com deficiência continuarão excluídas dentro do processo educacional inclusivo.

Neste contexto, Freire (2002, p. 11) afirma que não é apenas a educação que mudará os rumos da história, mas que a educação verdadeira (a problematizadora ou libertadora) conscientiza a respeito das contradições do mundo humano que impelem o homem a ir adiante. A acomodação torna-se impraticável e o método pedagógico caminha para a práxis da liberdade. Esta seria a busca da emancipação social, de uma sociedade boa (emancipada) em uma democracia efetiva, a qual é delineada por Boaventura de Sousa Santos:

Enquanto o Estado de Direito e a reforma judicial são, hoje em dia, tópicos de debate em todo o sistema-mundo, já toda e qualquer discussão acerca da emancipação social se vê suprimida pela globalização neoliberal, uma vez que, segundo esta, a ordem e a sociedade boas já estão conosco, carecendo apenas de consolidação (SANTOS, 2003, p. 11).

O Brasil tem uma vasta e rica legislação, especialmente no que tange aos direitos da educação inclusiva das pessoas com deficiência. Portanto, essa ampla ordem normativa carece de consolidação e ações além do plano legal. São necessárias ações e políticas públicas para fortalecer e estabilizar a inclusão escolar.

Com base no mesmo autor (SANTOS, 1999b, p. 22), observam-se indeterminações ao se articular a inclusão: “em condições de aceleração da história como a que hoje vivemos é possível pôr a realidade no seu lugar sem correr o risco de criar conceitos e teorias fora do lugar?’. A educação humanista e libertadora de Freire, (2002, p. 43) reitera que o importante é que os homens submetidos à dominação, lutem por sua emancipação.

Inúmeras colaborações à construção da cidadania e emancipação social serão possibilitadas através da forma individualizada de atendimento ao aluno que necessita de tratamento diferenciado. Paulo Freire (2002, p. 40) preleciona que "a educação problematizadora, 
de caráter autenticamente reflexivo, implica num constante ato de desvelamento da realidade". Para ele, o resultado da inserção crítica da realidade se dá pela emersão da consciência.

Com a implementação efetiva das leis que disciplinam a inclusão, haveria maior possibilidade de se promover uma pedagogia humanizadora entre educador-educando. Isso possibilitaria também a emancipação desse sujeito acometido de certos impedimentos, que, muitas vezes, dificultam seu desenvolvimento.

A Lei 13.146/15 - Lei Brasileira de Inclusão da Pessoa com Deficiência (LBI) trouxe inovações e novas perspectivas às questões relativas à educação inclusiva. Estabeleceu parâmetros quanto ao fim do ensino especial com o objetivo de incluir e melhorar a educação àqueles que mais necessitam. Deste modo, a educação inclusiva merece ser explorada com lentes ampliativas sob uma ótica reinterpretativa e transformativa para a real e adequada aplicabilidade da Lei 13.146/15.

No entanto, por conta da desatenção com o desenvolvimento educacional do país, o Estado se demonstra incapaz de promover tal inserção e eficaz acessibilidade (IBGE, 2017). O valor oculto que há por trás das leis, principalmente aquelas que determinam e asseguram direitos fundamentais sociais, deve ser observado para que não ocorram omissões em detrimento da efetivação destes direitos. Ações e políticas públicas eficazes e capazes de promover a verdadeira inclusão escolar são decisivas neste processo.

Assim, apesar de o Estado instituir inúmeras normas e diretrizes para a inclusão escolar do aluno com deficiência, há ainda de fato, preconceitos, exclusões, falta de políticas públicas e falta de envolvimento de toda a sociedade, para que se promova a inclusão (AZEVEDO, 2019). Podem ser apontadas como consequências desta inefetividade: (1) alunos integrados apenas, mas não incluídos; (2) possível exclusão deste público; (3) evasão escolar das pessoas com deficiência e (4) emancipação social dissimulada pelo direito.

\section{Os entraves às políticas de educação inclusiva}

Apesar de ser bem regulamentada e instituída como uma política nacional, a educação inclusiva precisa de incentivos financeiros, metodológicos e curriculares para ser inserida de forma efetiva nas escolas do Brasil. De acordo com os especialistas da área, é preciso uma maior valorização da diferença como elemento central e deixar de lado a compartimentação dos conhecimentos pedagógicos para que os avanços sejam conquistados. 
A ausência de incentivos financeiros também se apresenta como um entrave para a instituição de uma educação efetivamente inclusiva (POULIN, 2018).

Outra barreira à educação inclusiva foi a Emenda Constitucional $n^{\circ}$ 95/16 (EC 95/16), a qual limitou as despesas com gastos sociais, como saúde e educação, congelando investimentos nessas áreas, por 20 anos, a despeito de ser tida como a forma ideal para um reequilíbrio fiscal estatal. Portanto, na verdade o que a sociedade brasileira vive hoje é um retrocesso social em pleno século XXI (LEAL, 2016). As dificuldades materiais são diversas e não há uma solução saudável em relação ao direito à educação.

O congelamento dos gastos pelo Governo Federal com a educação é um impedimento à efetivação da educação inclusiva. Assim, Santos (2003, p. 24) demonstra que devido ao crescimento da exclusão social no sul global, na qual se encontra a subclasse dos deficientes, é preciso enfrentar o fascismo social caracterizado pela relação de poder e trocas extremamente desiguais que conduzem a formas de exclusão severas e irreversíveis.

Para o autor (SANTOS, 2003, p. 21 - 23) há 4 formas de fascismo social: 1) Fascismo do apartheid social - divisão das cidades em zonas selvagens (estado natural hobbesiano) e zonas civilizadas (do contrato social); 2) Fascismo para-estatal (contratual e territorial) - usurpação das prerrogativas estatais, coerção e regulação social; 3) Fascismo da insegurança - manipulação do sentimento de insegurança dos grupos vulneráveis; 4) Fascismo financeiro (a mais pérfida) controla o mercado financeiro e sua economia de casino (capital especulativo dominante).

Esse fascismo social produziria então uma sociedade civil com divisão de classes. $\mathrm{O}$ autor (SANTOS, 2003, p. 7) afirma que vivemos num período de transição em que enfrentamos problemas modernos para os quais não existem soluções modernas. Que somos obcecados por uma ordem e uma sociedade boas, mas o que reina é a desigualdade e a exclusão.

O fascismo da insegurança, que abrange os grupos sociais mais vulneráveis, se enquadrando aqui as pessoas com deficiência deve ser enfrentado. Ao invés de se aplicar o princípio da igualdade material, o qual ensina o tratamento diferenciado a quem necessitar, o que ocorre é a aplicação da igualdade formal e discriminatória, elevando as desigualdades. Esse aumento das desigualdades leva ao fascismo social e à produção de uma sociedade civil estratificada, em que os indivíduos já discriminados se tornam cada vez mais invisibilizados. Isso seria mais um óbice à verdadeira inclusão. 
Quando entendemos que não é a universalidade da espécie que define um sujeito, mas as suas peculiaridades, ligadas a sexo, etnia, origem, crenças, tratar as pessoas diferentemente pode enfatizar suas diferenças, assim como tratar igualmente os diferentes pode esconder as suas especificidades e excluí-los do mesmo modo; portanto, ser gente é correr o risco de ser diferente (MANTOAN, 2006, p. 17).

Essa pode ser considerada a barreira da diversidade enfrentada nas escolas. Não se pode exigir que todas as pessoas sejam iguais em tudo. As metas do Plano Nacional de Educação (Lei 13.005/2014) visam à universalização do ensino, contudo, deve levar em consideração as diferenças existentes entre cada aluno. Mesmo que o educando não dependa de condição especial como àqueles com algum tipo de deficiência, é preciso um olhar diferenciado a cada indivíduo incluído no processo de desenvolvimento educacional.

Quando Boaventura de Souza Santos, 2003 se refere à exclusão social do Sul Global, ele inclui todas as classes das minorias excluídas historicamente e propõe a globalização contra hegemônica e o cosmopolitismo subalterno. Os discursos e as práticas políticojurídicas da globalização neoliberal são incapazes de enfrentar o fascismo social e de dar resposta à 'questão social' - (crescimento da sociedade civil incivil). O caráter estrutural da exclusão seria um dos obstáculos à inclusão (SANTOS, 2003, p. 20 e 26).

Verifica-se, portanto, que, ao se pensar no direito à educação em um país em desenvolvimento como o Brasil, a tarefa da inclusão das pessoas com deficiência se torna obscura e complexa. O desafio do direito social à educação, tem se mostrado a cada ano que passa, com mais obstáculos. O cenário atual brasileiro não é favorável e as pesquisas demonstram que o ensino no país está caótico. Segundo Rossieli Soares, Ministro da Educação, os resultados demonstrados pelo Ministério da Educação e Cultura (MEC), dos alunos das escolas públicas são desastrosos (VENEZA, 2018).

Não haveria que se esperar algo melhor de um Estado que, ao invés de aumentar os investimentos na educação, setor que emancipa e faz crescer o capital intelectual de um país, gerando maior desenvolvimento econômico-social, os reduz substancialmente. $\mathrm{O}$ direito à educação, como um direito humano internacionalmente reconhecido, não tem o valor e o tratamento que deveria no Estado brasileiro.

Ao se verificar um sistema educacional caótico no ensino básico e no tradicional, o que se pode concluir, infelizmente, é uma dificuldade ainda maior ao falarmos em investimentos e melhorias na educação especial. A inclusão escolar requer uma série de adequações do sistema 
para se promover: mudanças estruturais, práticas pedagógicas específicas, materiais didáticos, mudanças paradigmáticas, dentre outras.

Na visão de Moreira (2007, p. 58), o Estado democrático tem como um de seus fundamentos o princípio da igualdade de oportunidades e que as ações estatais devem objetivar a criação de estruturas que propiciem a participação igual de toda sociedade. E aqui temos mais um impedimento à inclusão escolar: se o Estado não está investindo o capital público no básico, sequer ocorrerá para a educação especial, que demanda maiores investimentos.

Toda sociedade e principalmente as famílias diretamente envolvidas com as questões educacionais devem buscar uma solução junto ao Poder Público, cobrar de seus representantes que se efetivem as leis e que se executem as normas. A educação não pode ficar à deriva como um simples direito fundamental banalizado diante do sistema normativo.

\section{A ineficiência das legislações educacionais inclusivas e os obstáculos à efetivação dos Direitos Humanos às pessoas com deficiência}

A sociedade caminha cada vez mais para o mundo do ter e se afasta subitamente do ser. O que se valoriza, muitas vezes, é o que se tem e não o que se é ou quem é. À vista disso, há que se avaliar o primeiro obstáculo à inclusão das pessoas com deficiência em uma sociedade que prima por aparências e por valores materiais e não humanos. A falta de solidariedade da sociedade, das famílias e do Poder Público seria um dos diversos impedimentos à efetivação do direito à educação inclusiva.

Solidariedade, numa concepção ética, significa colocar-se no lugar do "outro" e estabelecer laços recíprocos entre os membros de uma mesma comunidade, de maneira que todos possam participar, de forma compartilhada e cooperada, dos processos sociais. Hoje, porém, no mundo moderno, gerador e provocador de um comunismo desenfreado, desnecessário e fútil de bens materiais entre todas as camadas da população, que privilegia somente os que detêm capacidade econômica para tanto e que, em regra, se converte em instrumento de inclusão ou exclusão, estabelecer relações de solidariedade com o "outro", de forma a tratá-lo por igual, sejam quais forem suas necessidades de reconhecimento e diferenças, é algo que se queda em segundo (ou último?) plano para muitos (MADRUGA, 2016, p.77).

De que adiantam leis que objetivam incluir essas pessoas, se a própria sociedade irá excluí-las de alguma forma, seja na escola, na família, na universidade ou no mercado de 
trabalho? Este mundo acelerado que se vive hoje, faz com que o outro seja esquecido, que sejam invisibilizados aqueles que estão fora do padrão da normalidade. Não há tempo a perder, não há tempo para se notar os detalhes e a diversidade, não há tempo para tentar entender as diferenças existentes nos seres humanos.

Com a universalização da educação tentou-se promover a igualdade desse direito social. No entanto, algumas dificuldades foram encontradas neste percurso homogeneizador. Não se atentou para as singularidades e diferenças existentes em cada ser, não apenas as disparidades físicas, mentais, mas também socioculturais. A não percepção das diferenças e a não observância ao princípio da igualdade substancial é outro entrave ao direito inclusivo da pessoa com deficiência.

El plano social de la problematica nos hace dar un paso adelante. ya no se trata de analizar las tendencias homogeneizadoras que pretenden aparentemente evitar las discriminaciones, con el efecto perverso de reducir a ceniza las diferencias e imponer una sola visión del mundo como la universal. Se trata ahora de contraponer los conceptos de igualdad y desigualdade (FLORES, 2010, p. 116)

A educação como direito humano é responsável pela efetivação de outros diversos direitos exercidos pelos cidadãos (BITTAR, 2014, p. 22). Nessa perspectiva, Boaventura de Souza Santos traça as tensões da modernidade e os direitos humanos que se transformaram, nas duas últimas décadas, em quase sinônimo de emancipação social. Segundo o autor, a aplicação dos Direitos Humanos não é universal (SARMENTO, 2010, p. 3 e 13). O direito poderá ser emancipatório se as leis forem aplicadas atingindo sua eficácia social.

Após 70 anos de existência, a DUDH não se apresenta de maneira tão robusta como deveria. Segundo Rajagopal (2005, 205-208), enxergar os Direitos Humanos como único discurso de emancipação e resistência para a classe dos oprimidos do terceiro mundo, não é a melhor forma de se tentar resolver o problema social da exclusão e da desigualdade.

O autor afirma que os Direitos Humanos têm muitos elementos que são descendentes da ideologia e das práticas coloniais (modelo eurocêntrico criticado por Boaventura de Sousa Santos, no qual ele sugere as epistemologias do Sul e uma globalização contra hegemônica.).

\footnotetext{
${ }^{2}$ Tradução livre: "O nível social do problema nos faz dar um passo à frente. não se trata mais de analisar as tendências homogeneizantes que aparentemente procuram evitar a discriminação, com o efeito perverso de reduzir as diferenças às cinzas e impor uma visão única do mundo como universal. Agora é uma questão de contrastar os conceitos de igualdade e desigualdade".
} 
Então ele conclui que ao se estabelecer o discurso dos Direitos Humanos como único, corre-se o risco de reproduzir muitos erros do governo colonial (RAJAGOPAL, 2005, p. 210). Sendo assim, o país não avança pelo simples motivo de se ter muitas e boas leis, se, de fato, estas não surtirem o efeito prático esperado.

Ocorre que, se as legislações surtissem o efeito não apenas jurídico, mas principalmente o efeito social, poderia se pensar em algum avanço dos Direitos Humanos da pessoa com deficiência e da sua emancipação social. O desenvolvimento dos alunos com alguma deficiência está diretamente ligado à sua formação cidadã dentro do ambiente escolar e também fora dele. Para tanto, diversas normas foram elaboradas com a intenção de incluir estas pessoas.

Contudo, o que se nota é a negação da diferença e a permanência da invisibilidade. As leis trazem a inclusão de forma geral, ficando ao arbítrio dos governantes implementá-las de acordo com suas reservas financeiras, que são sempre um entrave à efetivação dos direitos sociais. Com isso, os já excluídos continuam ocultos aos olhos da sociedade e do Poder Público.

Invisibilidade significa aqui que o sofrimento humano de certos segmentos da sociedade não causa uma reação moral ou política por parte dos mais privilegiados e não desperta uma resposta adequada por parte dos agentes públicos (VIEIRA, 2010, p. 207)

Diante das escolhas que muitas vezes o Poder Público deve fazer para concretização dos direitos sociais, os invisibilizados ficarão, certamente, para último plano. As complexidades materiais e escassez de recursos públicos, outros óbices à inclusão escolar, prejudicam significativamente a efetivação à inclusão escolar do aluno com deficiência.

Entretanto, a carência de recurso não pode ser um motivo de ocultação da necessidade de se fazer algo para alterar esse cenário atual da educação brasileira. $\mathrm{O}$ direito à educação é importante para a emancipação social e à efetivação da democracia.

A seguir, e assumindo o risco, gostaria de apresentar a minha concepção inicial de educação. Evidentemente não a assim chamada modelagem de pessoas, porque não temos o direito de modelar pessoas a partir do seu exterior; mas também não a mera transmissão de conhecimentos, cuja característica de coisa morta já foi mais do que destacada, mas a produção de uma consciência verdadeira. Isto seria inclusive da maior importância política; sua idéia, se é permitido dizer assim, é uma exigência política. Isto 
é: uma democracia com o dever de não apenas funcionar, mas operar conforme seu conceito, demanda pessoas emancipadas. Uma democracia efetiva só pode ser imaginada enquanto uma sociedade de quem é emancipado (ADORNO, 1995, p. 64).

A inclusão social das pessoas com deficiência não pode ser uma mera ideologia ou utopia. Não se pode pensar num mundo que pensa apenas no capital, como pontua Sousa (2010, 9. 69). Na visão da autora, “o utilitarismo lucrativo passou a ser a única 'ética' prezada e reverenciada"

A educação seria impotente e ideológica se ignorasse o objetivo de adaptação e não preparasse os homens para se orientarem no mundo. Porém ela seria igualmente questionável se ficasse nisto, produzindo nada além de well adjusted a people, pessoas bem ajustadas, em conseqüência do que a situação existente se impõe precisamente no que tem de pior. Nestes termos, desde o início existe no conceito de educação para a consciência e para a racionalidade uma ambigüidade. Talvez não seja possível superá-la no existente, mas certamente não podemos nos desviar dela (ADORNO, 1995, p. 65).

A educação especial para pessoas com deficiência tem que ser analisada sob a ótica do princípio da igualdade material. Na visão de Mello (2013, p. 10), “a lei não deve ser fonte de privilégios ou perseguições, mas instrumento regulador da vida social que necessita tratar equitativamente todos os cidadãos". As relações sociais e os Direitos Humanos devem ser congruentes a um Estado Democrático de Direito. O desenvolvimento humano e a cidadania integram o desenvolvimento social do país e estão diretamente ligados à qualidade de uma vida digna e à justiça social.

Planos de ação devem ser traçados para que seja efetivada a inclusão dos alunos com deficiência na rede regular de ensino. Para Rajagopal (p. 261-262) uma área notável em que os direitos humanos estão gradualmente passando por uma "transformação desenvolvimentista" é a elaboração de Planos de Ação Nacionais para os Direitos Humanos (PANDH) por vários países. A Conferência de Viena sobre os Direitos Humanos de 1993 convidaram os Estados a desenvolver planos com o propósito de estabelecer prioridades nacionais concretas e procedimentos para obtê-las.

De acordo com o relatório divulgado em 2018, referente aos anos de 2016 e 2017, no ranking do Índice de Desenvolvimento Humano Ajustado à Desigualdade - IDHAD, o Brasil ficou estagnado e caiu do $10^{\circ}$ para o $9^{\circ}$ país mais desigual (OXFAM, 2018). Se a análise for 
feita pelo Índice de Desenvolvimento Humano - IDH, o Brasil ocupa o $79^{\circ}$ lugar, sendo considerado um país com médio desenvolvimento humano (ONU, 2018). É certo que isso dificulta bastante o processo educacional inclusivo, mas, por outro lado, demonstra a urgência em se adotar políticas públicas que minimizem esses quadros desfavoráveis de um Estado que se diz democrático.

Portanto, não faltam razões para se repensar e investir no direito à educação, principalmente na educação inclusiva. As pessoas com deficiência, se incentivadas e estimuladas para uma vida igual com suas diferenças, serão incluídas, não apenas nas escolas, mas em toda sociedade. A elas será dada a oportunidade de fazer parte, não apenas da ordem social, mas também da ordem econômica do país.

\section{CONCLUSÃO}

Os desafios educacionais vêm se agravando a cada dia, e o Estado e a sociedade não podem se vendar quanto a essa questão alarmante. O Brasil caminha na contramão em relação ao direito à educação e o retrocesso social toma relevo. Um país em desenvolvimento necessita de mais educação para que o seu povo se emancipe socialmente e para que a sociedade seja mais justa, igual e livre. O Estado, por mais capitalista, deve investir no direito social à educação que é essencial à promoção da evolução da humanidade.

Toda norma jurídica produzida pelo Estado deve levar em consideração a vida social do indivíduo e sua real inserção na sociedade. A eficácia jurídica de uma norma é importante, mas o ideal é que este efeito seja harmonizado à sua eficácia social.

Pôde-se perceber a partir desta revisão de literatura, que muitas vezes, a elaboração de diversas leis não é o suficiente para garantir, melhorar ou legitimar verdadeiramente um direito. Especialmente no que se refere à educação inclusiva a realidade se torna mais difícil, já que, historicamente, há uma forte exclusão e preconceitos de toda ordem contra as pessoas com deficiência.

A prática inclusiva envolve um repensar da política educacional, da política social, da política econômica e de toda sociedade. No entanto, não há que se falar em educação e inclusão sem investimentos em políticas públicas eficazes.

Os entraves à inclusão escolar dos alunos com deficiência são de ordem econômica, social e política, o que torna o sonho da verdadeira inclusão mais distante. Portanto, o Estado 
juntamente com toda sociedade deve se articular com estratégias que façam prosperar a finalidade inclusiva educacional. Certamente, esse é o caminho para uma nação se desenvolver socialmente.

\section{REFERÊNCIAS BIBLIOGRÁFICAS}

ADORNO, Theodor W. Educação e Emancipação. $3^{\text {a }}$ Ed. São Paulo: Paz e Terra, 1995. Tradução de Wolfgang Leo Maar. Disponível em: http://www.verlaine.pro.br/txt/pp5/adornoeducacao.pdf. Acesso em: 07 abr. 2019.

BRASIL. Constituição da República Federativa do Brasil de 1988. Disponível em: http://www.planalto.gov.br/ccivil_03/constituicao/constituicao.htm. Acesso em: 05 abr. 2018.

BRASIL. Lei no . 4.024, de 20 de dezembro de 1961. Lei de Diretrizes e Bases da Educação Nacional (LDBEN). Disponível em: http://www.planalto.gov.br/ccivil_03/LEIS/L4024.htm. Acesso em: 08 abr. 2019.

BRASIL/MEC. Lei nº 9.394, de 20 de dezembro de 1996. Lei de Diretrizes e Bases da Educação Nacional (LDB). Brasília, DF: 20 de dezembro de 1996.

BRASIL/MEC. Lei $n^{\circ}$. 13.146, de 6 de julho de 2015. Lei Brasileira de Inclusão da Pessoa com Deficiência. Brasília, DF: 6 de julho de 2015.

BRASIL/MEC. Lei no ${ }^{\circ}$ 13.005, de 25 de junho de 2014. Plano Nacional de Educação (PNE). Brasília, DF: 25 de junho de 2014.

BRASIL. Ministério da Educação. Secretaria de Educação Especial. Marcos Político-Legais da Educação Especial na Perspectiva da Educação Inclusiva / Secretaria de Educação Especial. - Brasília: Secretaria de Educação Especial, 2010.

EPSTEIN, Lee; KING, Gary. Pesquisa Empírica em Direito: as regras de inferência. São Paulo: Direito GV, 2013.

FLORES, Joaquín Herrera. La Construcción De Las Garantías. Hacia Uma Concepción Antipatriarcal De La Libetad Y La Igualdad. In: SARMENTO, D. et al (Org.). Igualdade, Diferença e Direitos Humanos. $2^{a}$ tiragem. Rio de Janeiro: Lumen Juris, 2010. p. 111-146.

FREIRE, Paulo. Pedagogia do Oprimido. 32. ed. Rio de Janeiro: Paz e Terra, 2002.

GUGEL, Maria Aparecida. A pessoa com deficiência e sua relação com a história da humanidade. Florianópolis: Obra Jurídica, 2007. Disponível em: http://www.ampid.org.br/ampid/Artigos/PD_Historia.php\#autor. Acesso em: 08 abr. 2019.

IBGE. Pessoas com deficiência: adaptando espaços e atitudes. 20 set. 2017. Disponível em: https://agenciadenoticias.ibge.gov.br/agencia-noticias/2012-agencia-denoticias/noticias/16794-pessoas-com-deficiencia-adaptando-espacos-e-atitudes. Acesso em: 14 mar. 2019. 
IBGE. Analfabetismo cai em 2017, mas segue acima da meta para 2015. 18 mai. 2018. Disponível em: https://agenciadenoticias.ibge.gov.br/agencia-noticias/2012-agencia-denoticias/noticias/21255-analfabetismo-cai-em-2017-mas-segue-acima-da-meta-para-2015. Acesso em: 19 mar. 2019

LEAL, Gabriel Prado. A (re)construção dos direitos sociais no século XXI : entre a progressividade, a estabilidade e o retrocesso. Jul. 2016. Disponível em: http://www2.senado.leg.br/bdsf/handle/id/525423. acesso em: 11 abr. 2019.

MANTOAN, Maria Teresa Edler. Inclusão escolar: pontos e contrapontos. São Paulo: Summus, 2006.

MELLO, Celso Antônio Bandeira de. O conteúdo jurídico do princípio da igualdade. 3. ed.São Paulo: Malheiros, 2013.

MITTLER, Peter. Educação inclusiva: contextos sociais / Peter Mittler; trad. Windz Brazão Ferreira. - Porto Alegre: Artmed, 2003.

MOREIRA, Orlando Rochadel. Políticas públicas e direito à educação. Belo Horizonte: Fórum, 2007.

NUSSBAUM, Martha C. Educação para o lucro, Educação para a Liberdade. Revista

Redescrições - Revista online do GT de Pragmatismo de Filosofia Norte-americana, v. 1, n. 1, 2009. Disponível em:

<http://www.gtpragmatismo.com.br/redescricoes/redescricoes/01/5Nussbaum.pdf $>$. Acesso em: 25 abr. 2018.

Sem fins lucrativos: Porque a democracia precisa das humanidades. São Paulo:

Martins Fontes, 2015.

ONU. IDH 2018: Brasil ocupa a 79ª posição. Relatório das Nações Unidas.

- São Paulo, 14 set. 2018. Disponível em: https://noticias.uol.com.br/internacional/ultimasnoticias/2018/09/14/idh-2018-brasil-ocupa-a-79-posicao-veja-a-lista-completa.htm. acesso em: 10 abr. 2019.

OXFAM. Renda recua e Brasil se torna o $9^{\circ}$ país mais desigual. Organização Oxfam Brasil, 2018. Disponível em: http://agenciabrasil.ebc.com.br/direitos-humanos/noticia/201811/renda-recua-e-Brasil-se-torna-o-9\%C2\%BA-pa\%C3\%ADs-mais-desigual. Acesso em: 2 abr. 2019.

POULIN, Jean-Robert. Educação Inclusiva demanda formação profissional e investimentos. Colóquio Internacional Sesc-UFC sobre Inclusão Social e Diversidade na Educação. 02 fev. 2018. Disponível em:

<https://www.opovo.com.br/jornal/cidades/2018/02/educacao-inclusiva-demanda-formacaoprofissional-e-investimentos.html>. Acesso em: 25 mar. 2019. 
O alerta de Jean-Robert Poulin sobre a educação inclusiva. 26 nov. 2013.

Disponível em: https://jornalggn.com.br/inclusao/o-alerta-de-jean-robert-poulin-sobre-aeducacao-inclusiva/. Acesso em: 11 abr. 2019

RAJAGOPAL, Balakrishnan. EI Derecho Internacional Desde Abajo: El Desarrollo, Los Movimientos Sociales Y La Resistencia Del Tercer Mundo. Colección En Clave de Sur. $1^{\text {a }}$ ed. Bogotá: ILSA, 2005. Cap. 7 p. 205 - 268.

RODRIGUES, David. Inclusão e Educação: doze olhares sobre a Educação Inclusiva. São Paulo: Summus, 2006.

ROUSSEAU, Jean Jacques. Discurso sobre a origem e os fundamentos da desigualdade entre os homens. São Paulo: Martin Claret, 2009.

SANTOS, Boaventura de Souza. A construção multicultural da igualdade e da diferença. Oficina do CES n. o 135, Coimbra, Janeiro de 1999a.

. Para uma Concepção Intercultural dos Direitos Humanos. In: SARMENTO, D. et al (Org.). Igualdade, Diferença e Direitos Humanos. $2^{\text {a }}$ tiragem. Rio de Janeiro: Lumen Juris, 2010. p. 03-46.

Para uma Sociologia das Ausências e uma Sociologia das Emergências, Revista Crítica de Ciências Sociais, 63 | 2002, 237-280.

Pela mão de Alice. O social e o político na transição pós-moderna. 7. ed. Porto: Afrontamentos, 1999b.

. Poderá o Direito ser emancipatório? Revista Crítica de Ciências Sociais, n. 65, maio 2003, p. 3-76.

SOUSA, Eliane Ferreira de. Direito à educação: requisito para o desenvolvimento do País / Eliane Ferreira de Sousa. - São Paulo: Saraiva, 2010. - (Série IDP).

VENEZA, Portal. "Ensino Médio está no fundo do poço, diz ministro". Disponível em: https://www.portalveneza.com.br/ensino-medio-esta-no-fundo-do-poco-diz-o-ministro/. Acesso em: 03 mar. 2019.

VIEIRA, Oscar Vilhena. A Desigualdade e a Subversão do Estado de Direito. In: SARMENTO, D. et al (Org.). Igualdade, Diferença e Direitos Humanos. $2^{\mathrm{a}}$ tiragem. Rio de Janeiro: Lumen Juris, 2010. p. 191-216. 